\title{
Schistosoma japonicum infections in cattle and water buffaloes of farming communities of Koronadal City, Philippines
}

\author{
Jan Clyden B. Tenorio ${ }^{1}$ and Elizabeth C. Molina ${ }^{1,2}$
}

1. Department of Paraclinical Sciences, College of Veterinary Medicine, University of Southern Mindanao, Kabacan, Cotabato, Philippines; 2. Cotabato Agriculture, Aquatic and Natural Resources Research and Development Consortium, University of Southern Mindanao, Kabacan, Cotabato, Philippines.

Corresponding author: Jan Clyden B. Tenorio, e-mail: jcbtenorio@usm.edu.ph

Co-author: ECM: emolina@usm.edu.ph

Received: 02-12-2019, Accepted: 31-01-2020, Published online: 02-03-2020

doi: www.doi.org/10.14202/IJOH.2020.28-33 How to cite this article: Tenorio JCB, Molina EC (2020) Schistosoma japonicum infections in cattle and water buffaloes of farming communities of Koronadal City, Philippines, Int. J. One Health, 6(1): 28-33.

\begin{abstract}
Background and Aim: Schistosomiasis is one of the seven neglected tropical diseases that are of public health concern in the Philippines. The disease is prevalent in few of the barangays (communities) in Koronadal City, Philippines. Status of the Schistosoma japonicum infections in domestic animal reservoir host has yet to be explored in these endemic communities. The study aimed to determine the prevalence and infection intensity of the disease in cattle and water buffaloes of endemic communities of Koronadal City.
\end{abstract}

Materials and Methods: Schistosomiasis was investigated in 70 cattle and 38 water buffaloes from three endemic communities in Koronadal City. The copro-parasitological technique used was the formalin-ethyl acetate sedimentation method.

Results: $S$. japonicum infection was observed in $48.6 \%$ of cattle and $60.5 \%$ in water buffaloes. The bovine contamination index indicated that all infected animals released 3,505,500 eggs/day. On average, infected cattle released 1,674,500 eggs daily, while infected water buffaloes liberated 1,932,000 eggs in the environment daily.

Conclusion: Cattle and water buffaloes in these endemic areas are infected with $S$. japonicum. These animals release large numbers of eggs in the environment daily; hence, played an important role in disease transmission. Those living and working in endemic areas should be aware of the inherent dangers of the disease.

Keywords: one health, Philippines, Schistosoma japonicum, schistosomiasis, zoonotic parasitic diseases.

\section{Introduction}

Schistosomiasis is one of the seven neglected tropical diseases (NTDs) that are prevalent in the Philippines [1]. It is reported that it affects 207 million people across 76 countries [2]. There are six species that cause human schistosomiasis: Schistosoma mansoni, Schistosoma japonicum, Schistosoma haematobium, Schistosoma mekongi, Schistosoma intercalatum, and Schistosoma malayensis. Among these, S. japonicum is the only one that has been shown to have substantial zoonotic transmission [3]. Schistosomiasis japonica is known to be prevalent in China, the Philippines, and portions of the Indonesian archipelago [4].

In 2017, the World Health Organization [5] reported that 202.8 million people across 52 countries required prophylactic treatment. In the Philippines, the Schistosomiasis Control Program of the Department of Health (DOH) [6] reports that "S. japonicum infection is still endemic in 12 regions with 28 provinces, 190 municipalities, and 2230

Copyright: Tenorio and Molina. This article is an open access article distributed under the terms of the Creative Commons Attribution 4.0 International License (http://creativecommons.org/ licenses/ by/4.0/), which permits unrestricted use, distribution, and reproduction in any medium, provided you give appropriate credit to the original author(s) and the source, provide a link to the Creative Commons license, and indicate if changes were made. The Creative Commons Public Domain Dedication waiver (http:// creativecommons.org/ publicdomain/zero/1.0/) applies to the data made available in this article, unless otherwise stated. barangays (communities)." In 2018, a focal survey conducted by the $\mathrm{DOH}$ of the Philippines found that the national prevalence rate (PR) for schistosomiasis was $4.68 \%$ with 435 of the endemic barangays having $>5 \%, 357$ with $<5 \%$, and 379 with $<1 \%$ [6]. The major endemic areas include the islands of Leyte and Samar in the Visayan archipelago, and almost the entire island of Mindanao where there is no distinct dry season $[7,8]$.

The Provincial Health Office of South Cotabato Schistosomiasis Incidence Report [9] stated that S. japonicum infections are endemic in seven communities (barangays) of Koronadal City and seven communities in the Municipality of Tantangan with a total population at risk of infection at 82,803 . In the same year, there were nine reported cases of human schistosomiasis with Koronadal City having six and Tantangan having three [9]. No previous studies have looked into the status of the disease in possible animal reservoir hosts in these areas.

A comprehensive study that evaluated the status of schistosomiasis in potential animal reservoir hosts in Samar, the Philippines, posited that very few water buffaloes were infected as compared to dogs and rats [10]. Mathematical modeling of the parasite transmission further supports this claim [11]. However, recently, studies have reported that high PR of schistosomiasis were demonstrated in cattle [12] and 
water buffaloes [12-14] in Samar and Leyte. These authors employed molecular diagnostic assays and a novel copro-parasitological technique in the detection of the disease. Their observations suggested the potential role played by these animals in the disease transmission toward human inhabitants of endemic communities.

The study aimed to determine the prevalence and infection intensity of schistosomiasis in cattle and water buffaloes based on fecal egg counts using the formalin-ethyl acetate-sedimentation technique (FEA-SD). In addition, the study determined the significance of cattle and water buffaloes in the transmission of $S$. japonicum toward the environment.

\section{Materials and Methods}

\section{Ethical approval}

Ethical approval for all the procedures conducted in animals was provided by the Institutional Animal Care and Use Committee of the University of Southern Mindanao.

\section{Experimental approach}

A cross-sectional study was done in the barangays of Morales, Cacub, and Zone III, Koronadal City, South Cotabato Province (Figure-1). Formal communication was established with the City Veterinary Office and Local Community Offices of each barangays.

Cattle and water buffaloes listed in recent health records of the City Veterinary Office were selected and included in the study. A total of 108 animals were sampled. From these animals, 70 were cattle and 38 were water buffaloes. The sex and age of the animals were noted. All animals were grouped according to their age: $\leq 3$ years old for Group 1 ; and $>3$ years old for Group 2.

\section{Collection and examination of samples}

The collection of stool samples was done by direct insertion of a hand with gloves moistened with water into the rectum. One fecal sample was collected per animal studied. Fecal samples were placed in a clean disposable cup with lid and labeled accordingly. All samples were brought and examined at the Veterinary Parasitology Laboratory of the College of Veterinary Medicine, University of Southern Mindanao, Kabacan, Cotabato. Sample collection and analysis was done from June 2018 to August 2018.

\section{Parasitological examination technique}

The study used the novel copro-parasitological technique described by Xu et al. [15] for the detection of $S$. japonicum eggs in ruminant fecal samples, the FEA-SD technique with few modifications. The whole volume of the sample was read using a McMaster 4 chamber worm egg counting slide $4 \times 0.5 \mathrm{ml}$ (Whitlock Sfelo ${ }^{\circ}$ ). All of the samples were examined only once. Only one person read and counted the $S$. japonicum eggs.

\section{Statistical analysis}

The prevalence of $S$. japonicum infection among cattle and water buffaloes was determined based on the presence of schistosome eggs in fecal samples. Egg counts in $5 \mathrm{~g}$ of feces were noted. The age of the animals was tested in their significant association with the prevalence of $S$. japonicum infection. This was explored using Chi-square test. Specifically, infection intensity among individual cattle and water buffaloes within each endemic setting was determined based on

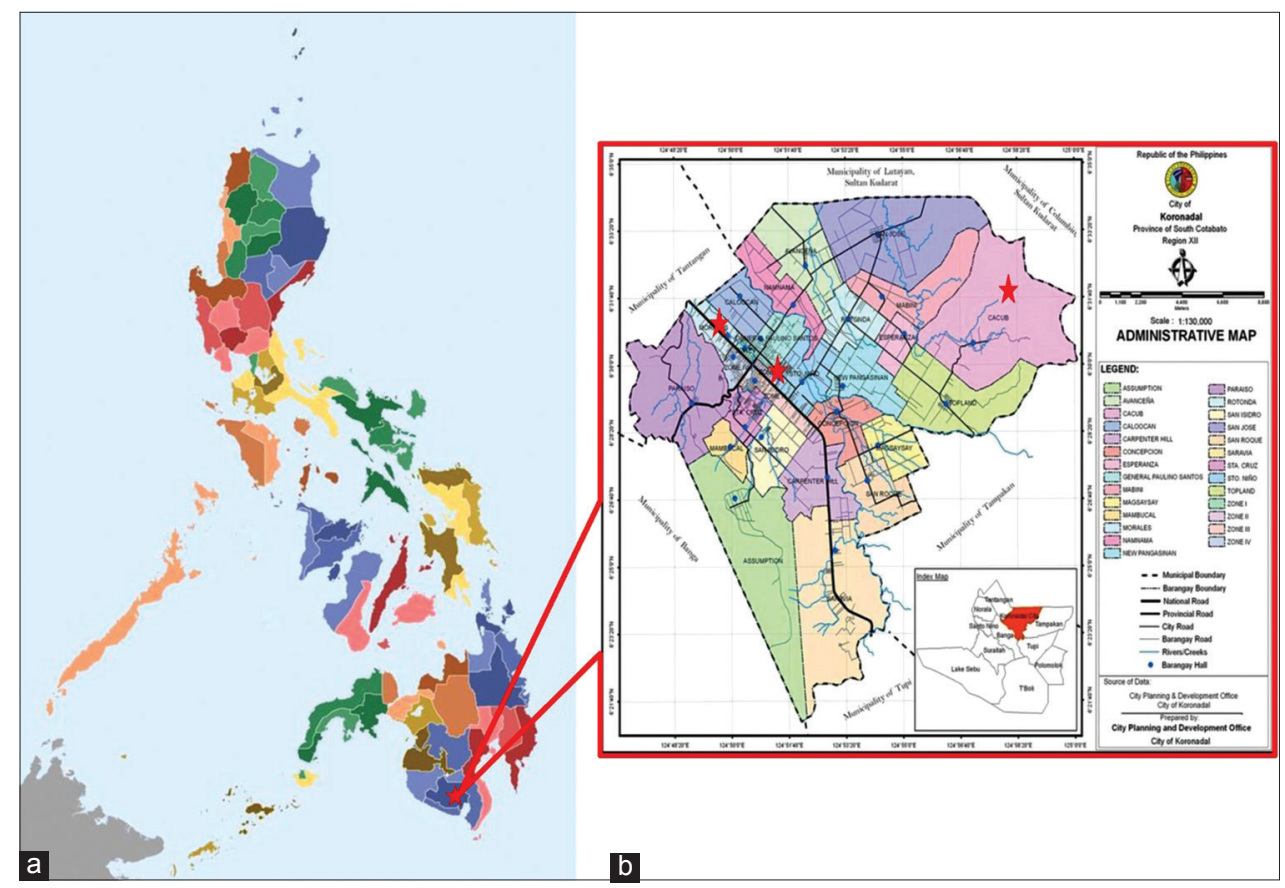

Figure-1: (a) Map of the Philippines highlighting the province of South Cotabato (in red star), where Koronadal City is situated (https://en.wikipedia.org/wiki/Template: Philippines_labelled_map); (b) map of Koronadal City highlighting the area sampled (in red star) (https://www.koronadal.gov.ph/wp-content/uploads/2019/04/operational-map-1024x918.jpg). 
the total egg count in $5 \mathrm{~g}$ of fecal samples. The intensity of infection was determined by egg counts in $5 \mathrm{~g}$ of feces and was categorized as light (1-400 eggs), moderate (101-400 eggs), or heavy (>400 eggs), as described by Ardina (2014). The mean of the egg counts between cattle and water buffaloes was subjected to a t-test for equality of means to determine whether there is a significant difference between the two. The bovine contamination index (BCI) per animal was measured as well as the overall BCI within each area.

PR

The PR of schistosomiasis within the cattle and water buffalo population was determined using the following formula:

$$
\mathrm{PR}=\frac{\text { No. of cases in the population at one time }}{\begin{array}{c}
\text { No. of animals in the population at the } \\
\text { same time }
\end{array}} \times 100
$$

BCI

The number of $S$. japonicum eggs excreted by each cattle and water buffalo, on an average, was calculated through the formula, as used by Gordon et al. (2012) [13]:

"BCI=Arithmetic mean of eggs per gram $(\mathrm{EPG}) \times$ Number of infected bovines $\times 25,000 \mathrm{~g}$ (average fecal weight)."

\section{Results}

There were 108 animals sampled included in the study. Of these, 70 were cattle and 38 were water buffaloes. When both species were considered, a total of 65 animals were aged $\leq 3$ years and 43 belonged to the age group $>3$ years. Among cattle, 42 belonged to animals aged $\leq 3$ years, while 28 animals aged $>3$ years. For water buffaloes, 24 animals were $\leq 3$ years of age, and 14 aged $>3$ years. A sample was deemed positive on identification of a schistosome egg (Figure-2).

\section{S. japonicum infection: Prevalence}

Using the FEA-SD method, fecal samples from both cattle and water buffaloes were examined for the presence of $S$. japonicum eggs. Among the total 108 samples, $57(52.8 \%)$ were found to harbor the infection and 51 were feco-negative. Among 70 samples from cattle, $34(48.6 \%)$ were positive. In water buffaloes, $23(60.5 \%)$ of the 38 samples were found to be feco-positive.

The results were examined through the chi-square test to determine the relationship between the species of the animal and $S$. japonicum infection (Table-1). The test revealed that the species of the animal is not associated with $S$. japonicum infection $(\mathrm{p}=0.128)$ suggesting that the species of the animal did not significantly influence the occurrence of infection.

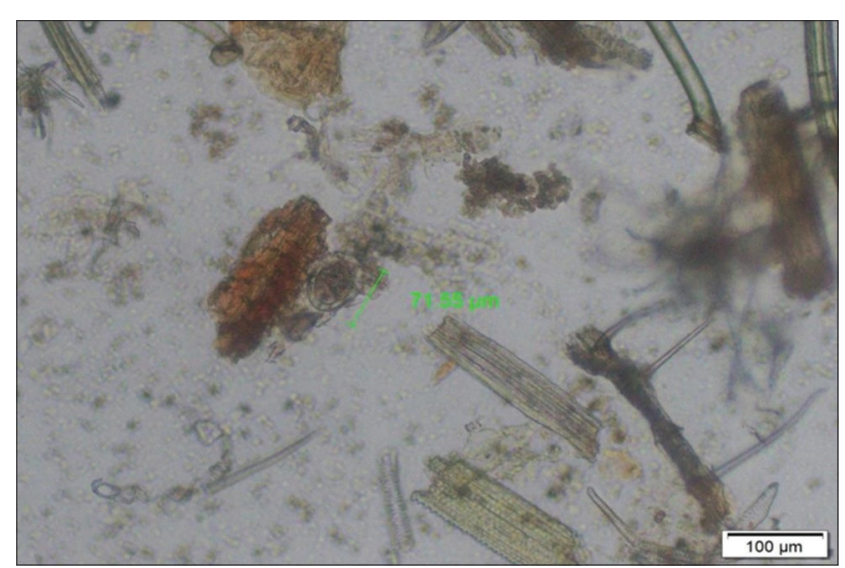

Figure-2: Schistosoma japonicum egg from a water buffalo feces $(100 \times)$.

Table-1: Prevalence of Schistosoma japonicum infection in cattle and water buffaloes in selected endemic communities in Koronadal City.

\begin{tabular}{|c|c|c|c|c|c|}
\hline \multicolumn{6}{|c|}{ Prevalence in relation to age } \\
\hline \multicolumn{6}{|c|}{ Total examined (in years) } \\
\hline$\leq 3$ & 65 & 35 & 53.8 & 0.075 & 0.785 \\
\hline$>3$ & 43 & 22 & 51.2 & & \\
\hline \multicolumn{6}{|c|}{ Cattle (in years) } \\
\hline$\leq 3$ & 42 & 18 & 42.9 & 1.166 & 0.280 \\
\hline$>3$ & 28 & 16 & 57.1 & & \\
\hline \multicolumn{6}{|c|}{ Water buffaloes (in years) } \\
\hline$\leq 3$ & 24 & 16 & 66.7 & 1.028 & 0.310 \\
\hline$>3$ & 14 & 7 & 50.0 & & \\
\hline
\end{tabular}

\begin{tabular}{lccccc}
\hline Species & \multicolumn{5}{c}{ Prevalence } \\
\cline { 2 - 6 } & $\mathbf{n}$ & $\begin{array}{c}\text { No. } \\
\text { positive }\end{array}$ & $\begin{array}{c}\text { Prevalence } \\
(\%)\end{array}$ & $\chi^{\mathbf{2} *}$ & p-value \\
\hline Total & 108 & 57 & 52.7 & 0.86 & 0.128 \\
examined & 70 & 34 & 48.6 & & \\
$\begin{array}{l}\text { Cattle } \\
\begin{array}{l}\text { Water } \\
\text { buffaloes }\end{array}\end{array}$ & 38 & 23 & 60.5 & & \\
\hline
\end{tabular}

*Chi-square test

\section{S. japonicum infection: Infection intensity}

Collectively, the intensity of infection in all animals was light with mean egg counts of 2.46. Mean egg count for cattle was 1.97 , while for water buffaloes, 3.36 (Table-2). t-test was done to evaluate if there is a significant difference in the egg counts between species. The result showed a significant difference $(\mathrm{p}=0.016)$ with water buffaloes having significantly higher mean egg counts compared to cattle.

\section{S. japonicum infection: Prevalence in relation to age}

When both species were considered, the prevalence was slightly higher for animals within the ages of 3 years and below (53.8\%) than those aging above 3 years $(51.2 \%)$, though this difference was found to be statistically insignificant $(\mathrm{p}=0.785)$ (Table-1). The prevalence of $S$. japonicum infection was not significantly associated with the age of the animal. In cattle, the result showed that those belonging to the ages of $>3$ years got a higher prevalence $(57.1 \%)$ than those aging $\leq 3$ years $(42.9 \%)$. This difference in prevalence 
Table-2: Intensity and t-test for equality of means conducted between the egg counts of cattle and water buffaloes sampled from selected barangays in Koronadal City.

\begin{tabular}{lcccc}
\hline Species & \multicolumn{4}{c}{ t-test for equality of means } \\
\cline { 2 - 5 } & MEPG* & t-value & df & p-value \\
\hline Cattle & 1.97 & 2.44 & 106 & 0.016 \\
Water buffaloes & 3.36 & & & \\
\hline * Mean egg count per $5 \mathrm{~g}$ of feces & &
\end{tabular}

Table-3: Bovine contamination index of S. japonicum infection in cattle and water buffaloes in selected barangays in Koronadal City.

\begin{tabular}{lcccc}
\hline Species & \multicolumn{4}{c}{ Bovine contamination index } \\
\cline { 2 - 5 } & MEPG* & $\begin{array}{c}\text { No. } \\
\text { positive }\end{array}$ & BCI overall & $\begin{array}{c}\text { BCI per } \\
\text { animal }\end{array}$ \\
\hline Cattle & 1.97 & 34 & $1,674,500$ & 49,250 \\
$\begin{array}{l}\text { Water } \\
\text { buffaloes }\end{array}$ & 3.36 & 23 & $1,932,000$ & 84,000 \\
$\begin{array}{l}\text { Total } \\
\text { examined }\end{array}$ & 2.46 & 57 & $3,505,500$ & 61,500 \\
\hline
\end{tabular}

*Mean egg count per $5 \mathrm{~g}$ of feces

is still insignificant $(p=0.280)$. Among water buffaloes, those aged $\leq 3$ years got a prevalence of $66.7 \%$, which was higher compared to those animals aged $>3$ years which got a prevalence of $50.0 \%$. Similarly, there was no significant relationship in the prevalence and age of the water buffaloes $(\mathrm{p}=0.310)$.

\section{S. japonicum infection: BCI}

The BCI, as shown in Table-3, gives an estimate of the quantity of schistosome eggs defecated by the animals studied. Results indicate that, on average, all the animals infected released 3,505,500 eggs/day in the environment. Each animal released 61,500 eggs in the environment. An estimated 1,674,500 eggs were excreted when all cattle were considered, while individually, 49,250 eggs were discharged per day. Water buffaloes, as a whole, liberated into the environment 1,932,000 eggs/day; and each water buffalo excreted 84,000 eggs. A large number of eggs released by these animals and the presence of the intermediate host in the areas studied demonstrate the potential role of cattle and water buffaloes in the S. japonicum infection transmission toward humans.

\section{Discussion}

Schistosomiasis is one of the predominant parasitic diseases in the world with 207 million persons in 76 countries reported to be affected [2]. In the Philippines, the schistosomiasis control program of the DOH [6] reports that $S$. japonica is still endemic in 12 regions out of the 16 regions of the country. According to the Provincial Health Office of South Cotabato Schistosomiasis Incidence Report [9], $S$. japonicum infections are endemic in seven barangays of Koronadal City. The detailed procedure for the FEA-SD technique is provided elsewhere [12].
Water buffaloes, and to a lesser extent cattle, are the known major animal reservoir hosts for $S$. japonicum infection in the marshlands and lake areas in Southwest China $[16,17]$. Hence, this study evaluated the infection in cattle and water buffaloes as these animals are likely to play a role in the transmission $S$. japonicum infection toward humans.

The total PR obtained (58.2\%) was not significantly lower than that reported by Gordon et al. in North Samar, the Philippines [12]. Using the same parasitological technique, they reported a prevalence of $62.1 \%$ in both cattle and carabaos. Among cattle, the prevalence obtained in the present study (48.6\%) was relatively higher than those reported in Ethiopia (4.5\%) [18] and Zimbabwe (4.5\%) [19]. However, these studies utilized less sensitive copro-parasitologic test that might have underestimated the actual degree of infection of the cattle studied. Islam et al. [20] similarly reported a higher prevalence of intestinal schistosomiasis (47.5\%) in cattle in Bangladesh. They noted that the frequent contact of cattle to snail infested bodies of water for drinking is a contributing factor to the continuous infection of these animals [20].

The MEPG showed a significant difference with water buffaloes having significantly higher mean egg counts compared to cattle $(\mathrm{p}=0.016)$. These differences could be attributed to the fact that water buffaloes, compared to cattle, spend much more time in water and marshy areas, which are their natural habitat and also where the infective stages of the parasite thrive. This contributes to substantially longer exposure to cercariae than cattle. Longer exposure would result in a higher magnitude of worm burden.

The result of the prevalence in relation to age differs from the findings of Gordon et al. [12], which reported a higher prevalence in animals aged more than 2 years old $(64.1 \%)$ than those aging 2 years and under $(55.6 \%)$. However, it has been reported that there is a decline in schistosome fecal egg counts as the animal ages. Dilution due to an increase in the fecal mass of the growing animal contributes to this inverse relationship [21]. Furthermore, there is a time-related immune suppression of fecundity that is observed in animals infected with $S$. mathei [22].

Among cattle, the difference in prevalence was similar to the observation of Bedarkar et al. [23] and Islam et al. [20]. They identified out that there is a positive correlation between age and rate of infection, with the highest infection rate occurring at maturity. In addition, De Bont et al. [24] also reported that the prevalence of schistosomiasis in younger animals was less compared to those at maturity. The higher prevalence in adults can be attributed to longer exposure time to infection in contaminated waterlogged areas. The extensive distances traversed by these animals in search of pasture and water increases the likelihood of acquiring the infection. Compared to adults, the very young calves do not graze extensively so they have fewer exposures to the infective stages of the parasite. 
The result of infection prevalence in relation to age among water buffaloes differs from what was observed by Ardina [25]. The author found that those aged $>8-12$ years had a higher prevalence $(57.14 \%)$ than the other younger age groups. However, Li et al. [26] identified an elevated PR of $S$. japonicum infection among water buffaloes aged $<12$ months as compared to older age groups. It had also been observed that calves are allowed to graze in the fields together with their dams, instead of being stall-fed. This practice increases the possibility of the calves acquiring the infection through exposure to the environment that is inhabited by the infective stage of the parasite.

A lower BCI was noted in the present study compared to those reported in the studies of Gordon et al. $[12,13]$. The BCI of individual water buffaloes was higher than those of cattle. This observation differs from the findings of Gordon et al. [12] wherein they indicated that each cattle had a BCI of 285,000 while a lower BCI of 137,500 was found for individual water buffaloes. The higher BCI in cattle may be due to the difference in susceptibility of cattle and carabaos to infection with $S$. japonicum, with the former being more prone to infection $[27,28]$.

A large number of eggs released and the presence of intermediate hosts in these areas further demonstrates the potential roles played by cattle and water buffaloes in the transmission of the S. japonicum toward humans. Those living and working in endemic areas should be aware of the inherent dangers of the disease.

\section{Conclusion}

This study concludes that $S$. japonicum infections are common in cattle and water buffaloes in the barangays of Morales, Cacub, and Zone III. The presence of schistosomiasis in the animals and the selectively high number of eggs excreted by infected animals studied suggest that these species play a potentially important role in human schistosomiasis transmission, as indicated by the previous studies.

Chemotherapy of the infected animals and humans is recommended. This multispecies approach could limit the $S$. japonicum infection in the environment. A snail control program may also be instituted in endemic barangays. Proper hygiene must be taken seriously in these endemic areas for unsanitary conditions that have been implicated in cases of human-tohuman transmission of the disease. Those working in environments that are favorable to the infective stage of the parasite must be knowledgeable of the inherent dangers of S. japonicum infection.

\section{Authors' Contributions}

JCBT and ECM designed the study. JCBT collected the samples and did the laboratory analysis. JCBT prepared the manuscript under the supervision of ECM. ECM sourced out funding for the research. Both authors read and approve the final draft of the manuscript.

\section{Acknowledgments}

The authors would like to extend their thanks to the City Veterinary Office of Koronadal City, Province of South Cotabato, Philippines for funding this study and their staff who assisted the researchers in the sample collection.

\section{Competing Interest}

The authors declare that they have no competing interests.

\section{Publisher's Note}

Veterinary World remains neutral with regard to jurisdictional claims in published map and institutional affiliation.

\section{References}

1. Fornillos, R.J.C., Fontanilla, I.K.C., Chigusa, Y., Kikuchi, M. and Kirinoki, M. (2019) Infection rate of Schistosoma japonicum in the snail Oncomelania hupensis quadrasi in endemic villages in the Philippines: Need for snail surveillance technique. Trop. Biomed., 36(2): 402-411.

2. Steinmann, P., Keiser, J., Bos, R., Tanner, M., \& Utzinger, J. (2006). Schistosomiasis and water resources development: systematic review, meta-analysis, and estimates of people at risk. The Lancet Infectious Diseases, 6(7), 411-425.

3. He, Y., Salafsky, B. and Ramaswamy, K. (2001) Hostparasite relationships of Schistosoma japonicum in mammalian hosts. Trends Parasitol., 17(7): 320-324.

4. Olveda, R.M. and Gray, D.J. (2019) Schistosomiasis in the Philippines: Innovative control approach is needed if elimination is the goal. Trop. Med. Infect. Dis., 4(2): 66.

5. Schistosomiasis. (2017) Available from: https://www. who.int/news-room/fact-sheets/detail/schistosomiasis.. Retrieved on 21-06-2018

6. Department of Health. n.d. (2019) Schistosomiasis Control Program. Available from: http://www.doh.gov.ph/schistosomiasis-comtrol-program. Retrieved on 30-10-2019.

7. Leonardo, L.R., Rivera, P., Saniel, O., Villacorte, E., Crisostomo, B., Hernandez, L., Baquilod, M., Erce, E., Martinez, R. and Velayudhan, R. (2008) Prevalence survey of schistosomiasis in Mindanao and the Visayas. Philipp. Parasitol. Int., 57(3): 246-251.

8. Leonardo, L., Rivera, P., Saniel, O., Villacorte, E., Lebanan, M.A., Crisostomo, B., Velayudhan, R. (2012) A national baseline prevalence survey of schistosomiasis in the Philippines using stratified two-step systematic cluster sampling design. J. Trop. Med., 2012: 1-8.

9. Provincial Health Office of South Cotabato. (2016) Schistosomiasis Incidence Report.

10. Fernandez, T., Tarafder, M., Balolong, E., Joseph, L., Willingham, A., Bélisle, P. and Carabin, H. (2007). Prevalence of Schistosoma japonicum infection among animals in fifty villages of Samar province, The Philippines. Vector Borne and Zoonotic Dis., 7(2): 147-155.

11. Riley, S., Carabin, H., Be'lisle, P., Joseph, L., Tallo, V., Balolong, E., Willingham III, A.L., Fernandez, T.J., Gonzales, R.O. and Olveda, R. (2008) Multihost transmission dynamics of Schistosoma japonicum in Samar Province, the Philippines. PLoS Med., 5(1): e18.

12. Gordon, C.A., Acosta, L.P., Gobert, G.N., Jiz, M., Olveda, R.M., Ross, A.G., Williams, G.M., Harn, D., Li, Y. and Mcmanus, D.P. (2015) High prevalence of Schistosoma japonicum and Fasciola gigantica in Bovines from Northern Samar, the Philippines. PLoS Negl. Trop. Dis., 9(2): e0003108.

13. Gordon, C.A., Acosta, L.P., Gray, D.J., Olveda, R.M., Jarilla, B., Gobert, G.N., Ross, A.G., Mcmanus, D.P. (2012) 
High prevalence of Schistosoma japonicum infection in Carabao from Samar Province, the Philippines: Implications for transmission and control. PLoS Negl. Trop. Dis., 6(9): e1778.

14. Wu, H., Qin, Y., Chu, K., Meng, R., Liu, Y., McGarvey, S.T., Olveda, R., Acosta, L., Ji, M.J., Fernandez, T., Friedman, J.F. and Kurtis, J.D. (2010) High prevalence of Schistosoma japonicum infection in water buffaloes in the Philippines assessed by real-time polymerase chain reaction. Am. J. Trop. Med. Hyg., 82(4): 646-652.

15. Xu, B., Gordon, C.A., Hu, W., Mcmanus, D.P., Chen, H., Gray, D.J., Ju, C., Zeng, X.J., Gobert, G.N., Ge, J., Lan, W.M., Xie, S.Y., Jiang, W.S., Ross, A.G., Acosta, L.P., Olveda, R. and Feng, Z. (2012) A novel procedure for precise quantification of Schistosoma japonicum eggs in bovine feces. PLoS Negl. Trop. Dis., 6(11): e1885.

16. Williams, G.M., Sleigh, A. C., Li, Y., Feng, Z., Davis, G.M., Chen, H., Ross, A.G., Bergquist, R. and Mcmanus, D.P. (2002) Mathematical modelling of Schistosomiasis japonica: Comparison of control strategies in the Peoples Republic of China. Acta. Trop., 82(2): 253-262.

17. Utzinger, J., Zhou, X., Chen, M. and Bergquist, R. (2005) Conquering schistosomiasis in China: The long march. Acta. Trop., 96(2-3): 69-96.

18. Chanie, G., Dejen, B. and Fentahun, T. (2012) Prevalence of cattle schistosomiasis and associated risk factors in Fogera cattle. J. Adv. Vet. Res., 2(1):153-156.

19. Pfukenyi, D.M., Makaratirwa, S., Willingham, A.L. and Monrad, J. (2006) Epidemiological studies of Schistosoma mattheei infections in cattle in the Highveld and Lowveld communal grazing areas of Zimbabwe. Onderstepoort $J$. Vet. Res., 73(3):179-191.

20. Islam, R.M., Iqbal, Z., Jabbar, A. and Yaseen, M. (2011)
Epidemiology of intestinal schistosomiasis in ruminants of Bangladesh. J. Helminthol., 81(3): 323-328.

21. De Bont, J., Vercruysse, J., Sabbe, F., Southgate, V.R. and Rollinson, D. (1995) Schistosoma mattheei infections in cattle: Changes associated with season and age. Vet. Parasitol., 57(4): 299-307.

22. Lawrence, J.A. (1977) Schistosoma mattheei in the ox: Observations on the parasite. Vet. Parasitol., 3(4):291-303.

23. Bedarkar, S.N., Narladkar, B.W. and Deshpande, P.D. (2000) Seasonal prevalence of snail fluke infections in ruminants of Marathwada region. J. Vet. Parasitol., 14(1): 51-54.

24. De Bont, J., Vercruysse, J. (1997) The epidemiology and control of cattle schistosomiasis. Parasitol. Today, 13(7): 255-262.

25. Ardina, N.Jr. (2014) Schistoma japonicum Infection in Swamp Buffaloes. Bubalus bubalis in Selected Barangays of Trento, Agusan Del Sur. Undergraduate Thesis. University of Southern Mindanao, Kabacan, Cotabato.

26. Li, Y.S., Sleigh, A.C., Ross, A.G., Williams, G.M., Tanner, M. and McManus, D.P. (2000) Epidemiology of Schistosoma japonicum in China: Morbidity and strategies for control in the Dongting Lake region. Int. J. Parasitol., 30(3): 273-281.

27. Wang, T., Zhang, S., Wu, W., Zhang, G. and Lu, D. (2006) Treatment and reinfection of water buffaloes and cattle infected with Schistosoma japonicum in Yangtze River valley, Anhui Province, China. J. Parasitol., 92(5): 1088-1091.

28. Yang, J., Fu, Z., Feng, X., Shi, Y., Yuan, C., Liu, J., Hong, Y., Li, H., Lu, K. and Lin, J. (2012) Comparison of worm development and host immune responses in natural hosts of Schistosoma japonicum, yellow cattle and water buffalo. BMC Vet. Re., 8(1): 25.

\section{$* * * * * * * *$}

